\title{
Binder of sperm 1 and epididymal sperm binding protein 1 are associated with different bull sperm subpopulations
}

\author{
Olivier D'Amours ${ }^{1}$, Louis-Jean Bordeleau ${ }^{1}$, Gilles Frenette ${ }^{1}$, Patrick Blondin ${ }^{2}$, Pierre Leclerc ${ }^{1}$ and \\ Robert Sullivan ${ }^{1}$ \\ ${ }^{1}$ Département d'Obstétrique-Gynécologie, Faculté de Médecine, Centre de Recherche du Centre Hospitalier de \\ I'Université Laval (CHUQ), Université Laval, 2705 Boulevard Laurier, Room T1-49, Québec City, Québec, Canada \\ G1V 4G2, and ${ }^{2} L^{\prime}$ Alliance Boviteq, Inc., St-Hyacinthe, Québec, Canada \\ Correspondence should be addressed to R Sullivan; Email: robert.sullivan@crchul.ulaval.ca
}

\begin{abstract}
Previously, we showed that binder of sperm 1 (BSP1) and epididymal sperm binding protein 1 (ELSPBP1) proteins are more abundant in the immotile bovine sperm subpopulation following cryopreservation. In this study, we investigated the association of BSP1 and ELSPBP1 with sperm in relation to their ability to survive the cryopreservation process. Fresh and cryopreserved semen samples from the same ejaculate collected from nine Holstein bulls were incubated with a fixable viability probe, fixed and permeabilised and then immunolabelled with rabbit anti-BSP1, rabbit anti-ELSPBP1 or rabbit IgG as negative control. Spermatozoa were then incubated with Alexa 488-conjugated secondary antibody and Hoechst 33342. For each sample, 10000 'Hoechst positive' events were analysed by flow cytometry. Alternatively, sperm populations were obtained by fluorescence-activated cell sorting. In freshly ejaculated live sperm, two distinct BSP1 detection patterns were revealed: a first population where BSP1 is present along the flagellar region (P1 subpopulation) and a second population where BSP1 is localised on both the flagellar and the acrosomal regions (P3 subpopulation). The dead population presented a BSP1 distribution similar to P3 but with a more intense fluorescence signal (P4 subpopulation). In the corresponding cryopreserved samples, all sperm in the P3 subpopulation were dead while only a small proportion of the P1 subpopulation was dead (P2 subpopulation). ELSPBP1 was detected only in dead spermatozoa and in comparable proportions in both freshly ejaculated and cryopreserved semen. These results show that the presence of BSP1 over the acrosomal region characterises spermatozoa sensitive to cryopreservation and that ELSPBP1 characterises spermatozoa that are already dead at ejaculation.
\end{abstract}

Reproduction (2012) 143 759-771

\section{Introduction}

Sperm cryopreservation implies dilution in the semen extender, cooling near the freezing point, freezing to stop cellular activity and thawing to regain normal functions (reviewed in Barbas \& Mascarenhas (2009)). Despite optimised protocols, cryopreserved semen has reduced fertility compared with freshly ejaculated one (Shannon \& Vishwanath 1995), arising from a combination of both loss in sperm viability and impairment of function in the survivors population (Den Daas et al. 1998). Damages are induced at each step of the cryopreservation process, and the functional state of frozen-thawed sperm is the result of injuries accumulated throughout the whole process (Medeiros et al. 2002).

Sperm membranes are thought to be the main site of cryoinjuries, with their lipid composition being the determinant of sperm sensitivity to cryopreservation. Important changes in temperatures during the cooling phase influence membrane properties by reducing membrane fluidity, leading to rearrangement of membrane components and lipid phase separation (De Leeuw et al. 1990). As temperature falls below the freezing point, spermatozoa are submitted to increasing molar concentration of cryoprotectants, inducing osmotic and toxic stresses. Thereafter, the plasma membrane has to support mechanical stress as ice is being formed in the extracellular environment (Sherman \& Liu 1982). Interspecies comparisons in sperm membrane lipid composition have highlighted the differences related to their sensitivity to cryopreservation: namely the relative proportion of phospholipid classes (De Leeuw et al. 1990), their degree of hydrocarbon chain saturation (Poulos et al. 1973) and the cholesterol/phospholipid ratio (Darin-Bennett \& White 1977). Among the same species, inter-individual variations are observed. Those individuals are either called 'good' or 'bad' freezers. This is in fact a 
manifestation of semen heterogeneity, as some spermatozoa survive the cryopreservation process while others do not.

Centrifugation of cryopreserved semen through a discontinuous percoll gradient allows separation of the motile from the immotile sperm populations (Parrish et al. 1995). Using this technique, we showed that two proteins, binder of sperm 1 (BSP1; accession number P02784) and epididymal sperm binding protein 1 (ELSPBP1; accession number NM_001192558), were more abundant in the immotile sperm population in bovine (D'Amours et al. 2010). Moreover, we found that levels of BSP1 in protein extracts from whole population of frozen spermatozoa negatively correlated with postthaw viability but not ELSPBP1. These results suggested that BSP1 is greatly associated with dead spermatozoa following cryopreservation while ELSPBP1 is associated with a subpopulation within the immotile population. BSP1 and ELSPBP1 are both fibronectin type 2 domaincontaining proteins (Esch et al. 1983, Saalmann et al. 2001), which gives affinity for choline head groups of membrane phospholipids (Wah et al. 2002). In bulls, BSP1 is secreted by the seminal vesicles and binds to the sperm surface at ejaculation (Manjunath \& Thérien 2002) while ELSPBP1 is secreted by the epididymis and is acquired by spermatozoa during epididymal maturation (Sahin et al. 2009).

The use of western blot to assess protein content in a sperm sample has limits as it does not give information on how heterogeneous is the sperm population. Moreover, it only allows indirect association with other physiological parameters. To encompass these limitations, the use of flow cytometry is an interesting alternative. Immunostaining on fixed sperm combined with flow cytometry has proven to be successful for the detection of ubiquitin and tyrosine phosphorylation in many mammalian species (Sutovsky et al. 2002, 2003, Piehler et al. 2006, Barbonetti et al. 2008). The availability of physiological probes that are not affected by standard fixation and permeabilisation procedures now allows probe combination with immunostaining to directly associate physiological states of spermatozoa with the presence of specific proteins (Martinez-Pastor et al. 2010).

As dead or immotile spermatozoa following cryopreservation contain higher amount of BSP1 and ELSPBP1, these two proteins might be promising markers of successful sperm cryopreservation in bovine. The objective of this study was to assess the presence of BSP1 and ELSPBP1 by flow cytometry on freshly ejaculated and cryopreserved bovine semen in order to validate their association with the sperm subpopulation sensitive to cryopreservation. This study also examines whether the potential for bovine spermatozoa to survive cryopreservation is acquired at the moment of ejaculation.

\section{Results}

\section{Specificity of antibodies and limitations of the immunocytometry assay}

In a first attempt to evaluate specificity of anti-ELSPBP1 and anti-BSP1, protein extracts from ejaculated sperm were separated by SDS-PAGE and transferred onto nitrocellulose membranes. Western blot with antiELSPBP1 revealed a doublet band around $31 \mathrm{kDa}$ (Fig. 1). This is in accordance with a previous report using a different antibody (Sahin et al. 2009). The antiBSP1 recognised a major band between 14 and $21 \mathrm{kDa}$ (Fig. 1), corresponding to the apparent molecular weight of BSP1 (Manjunath et al. 1987). A faint band was also detected slightly under $31 \mathrm{kDa}$. Purified BSP1 preparation from seminal plasma separated by SDS-PAGE and stained with Coomassie brilliant blue also showed a contaminant band slightly under the $31 \mathrm{kDa}$ molecular weight standard (not shown). This band was excised, trypsin digested and then identified by tandem mass spectrometry as BSP5 (accession number P81019). Thus, it is likely that the rabbit serum also contains antibodies directed against BSP5. As immunodetection of BSP5 is very low compared with BSP1, we assume that signal seen by immunofluorescence is due to the presence of BSP1 on sperm.

Figure 2 shows the detection of the three colours of the immunocytometry assay using detection of BSP1 on freshly ejaculated sperm as an example. To assess the

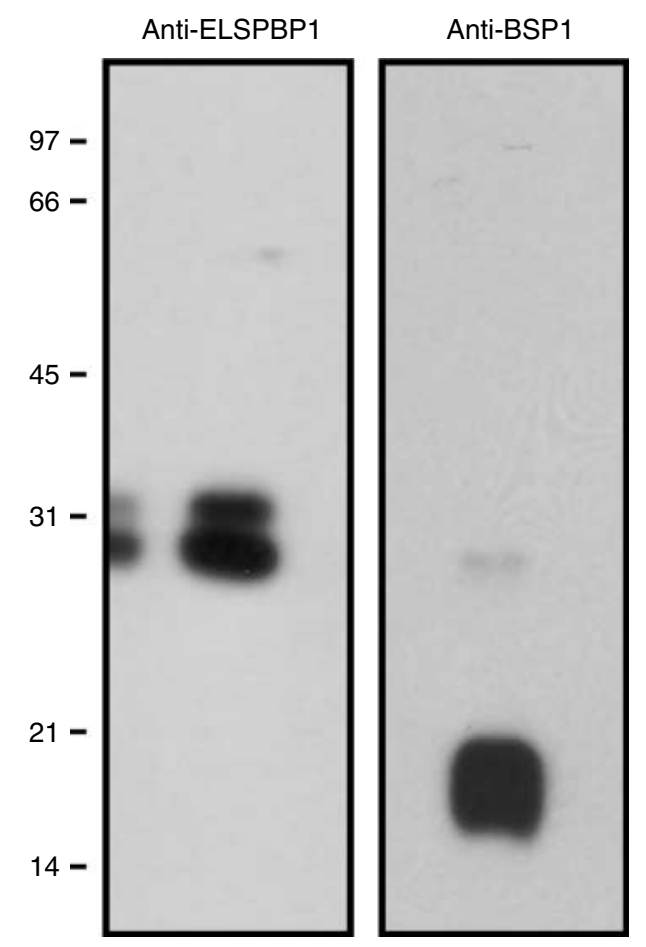

Figure 1 Western blot on ejaculated sperm protein extracts to assess specificity of the anti-ELSPBP1 and anti-BSP1. Molecular weight standards are indicated in the left side. 
reliability of the immunocytometry assay, viability was assessed at different steps of the immunofluorescence protocol. Immediately after ejaculation and after thawing, percentages of dead spermatozoa were $11.6 \% \pm 7.6$ and $37.2 \% \pm 4.2$ respectively. However, when fluorescence reading of the viability probe was assessed at the end of the immunocytometry protocol, which includes three washing steps, percentages of dead spermatozoa decreased to $7.5 \% \pm 6.2$ for freshly ejaculated sperm and $24.6 \% \pm 2.6$ for cryopreserved semen. In either freshly ejaculated or cryopreserved semen, a loss of about $30 \%$ dead spermatozoa was observed. This is due to the washing steps, where more dead spermatozoa seem to be lost during centrifugations. This is also due to the exclusion of aggregated sperm for the cytometry analysis (see Hoechst parameter in Fig. 2), which are mostly dead spermatozoa. Thus, percentages of the different subpopulations assessed by the immunocytometry assay do not reflect the real proportions at ejaculation or at thawing, with dead subpopulations probably underestimated at the expense of the live ones.

\section{Differences in the expression of BSP1 in sperm subpopulations}

For each of the nine ejaculates analysed, immunodetection by flow cytometry with anti-BSP1 antibody revealed three distinct levels of fluorescence in both freshly ejaculated and cryopreserved semen. When spermatozoa were distributed according to their BSP1 content and viability, three and four subpopulations were identified in freshly ejaculated and cryopreserved semen respectively (Fig. 3A). In freshly ejaculated sperm, these three subpopulations were arbitrarily named P1, P3 and P4. For each bull, live spermatozoa were distributed among $\mathrm{P} 1$ and $\mathrm{P} 3$, with the median fluorescence intensity (MFI) of P3 being $3.8 \pm 0.8$ times higher than P1 (Table 1). Dead spermatozoa formed the P4 subpopulation, which displayed $9.3 \pm 2.3$ times higher MFI than P1 (Table 1). In cryopreserved spermatozoa, four subpopulations were detected and named P1, P2, P3 and P4. Live spermatozoa were strictly present in $\mathrm{P} 1$ while dead spermatozoa were distributed among P2, P3 and P4 subpopulations. MFI of P2 was identical as the one displayed by P1 (P2/P1 ratio $=1.0 \pm$ 0.1 . Compared with P1, P3 showed $2.0 \pm 0.3$ times higher MFI while P4 showed $4.9 \pm 2.1$ times more intensity (Table 1). Thus, for both fresh and cryopreserved semen, low (P1 and P2), medium (P3) and high (P4) fluorescence intensity subpopulations were found, with P2 being present only in cryopreserved semen. MFI comparisons between pairs of populations before and after cryopreservation are shown in Fig. 4. Paired comparisons did not show significant differences in the intensity of fluorescence between P1 before cryopreservation and P1 or P2 after cryopreservation, which strongly suggests that P2 spermatozoa are derived from

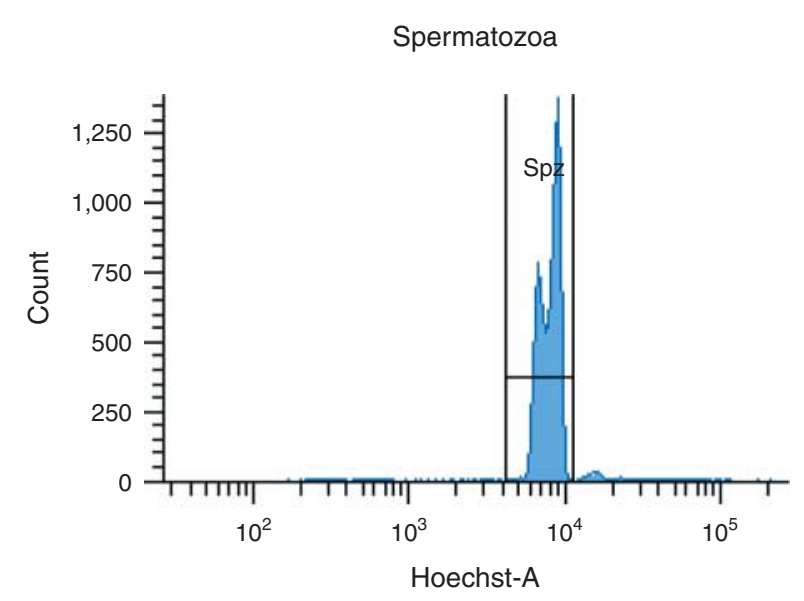

Protein detection
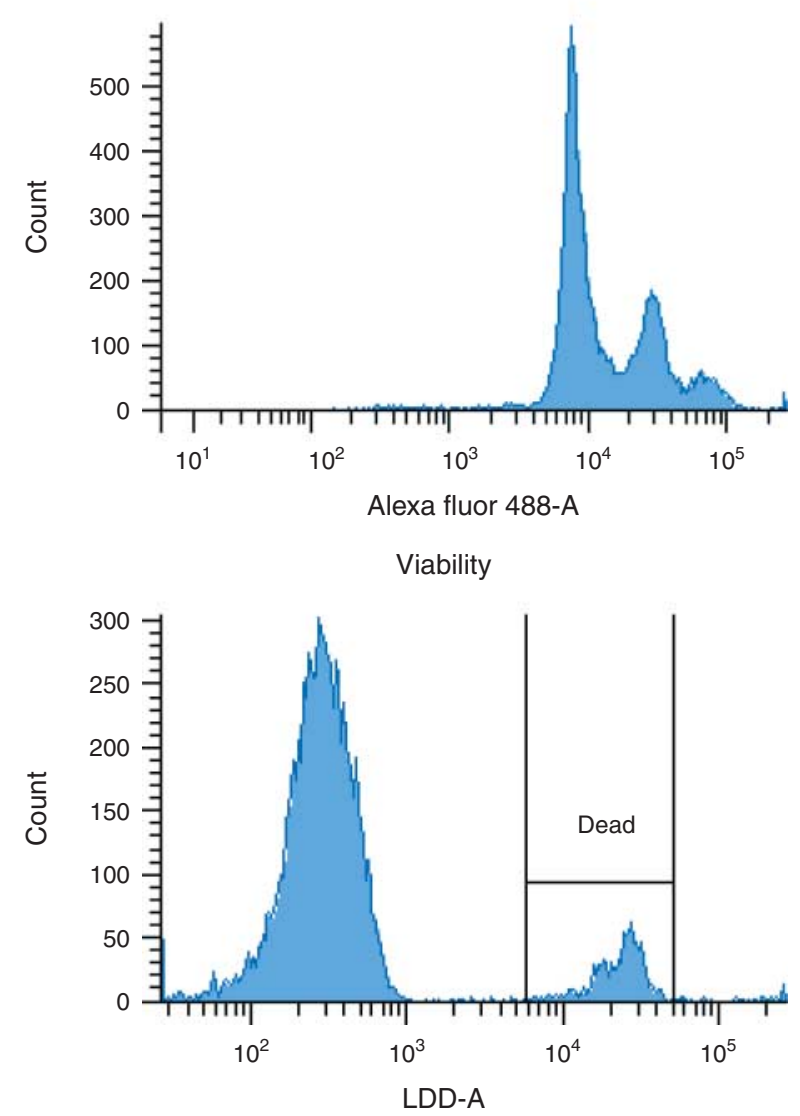

Figure 2 Fluorescence readings by flow cytometry of the three probes used in the immunocytometry assay. Example with BSP1 immunodetection on freshly ejaculated sperm. Fluorescence intensities are expressed as arbitrary units. Hoechst 33342 was used to discriminate spermatozoa (Spz) from debris and aggregated spermatozoa. Alexa 488-conjugated goat anti-rabbit was used to detect primary antibody. Spermatozoa having integrated LIVE/DEAD Fixable Near-IR Dead Cell Stain (LDD) were considered dead.

P1. However, a significant decrease was observed for P3 and P4 spermatozoa.

Localisation of BSP1 in spermatozoa was assessed after fluorescence-activated cell sorting of the different 
A

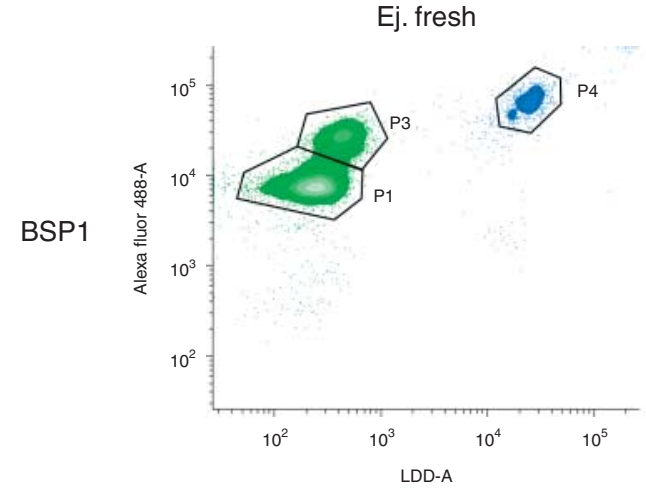

B

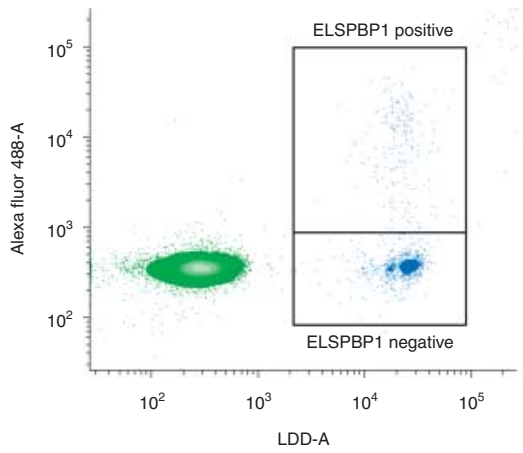

C

Rabbit lgG

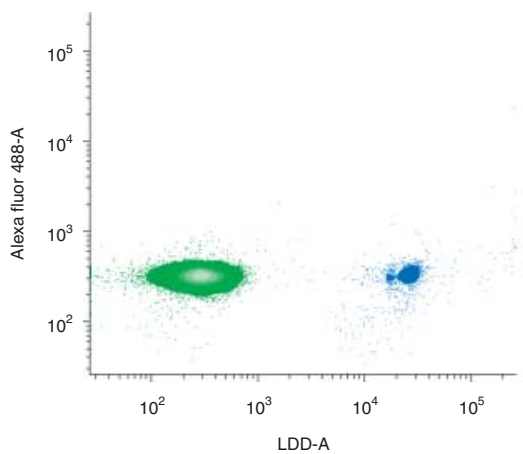

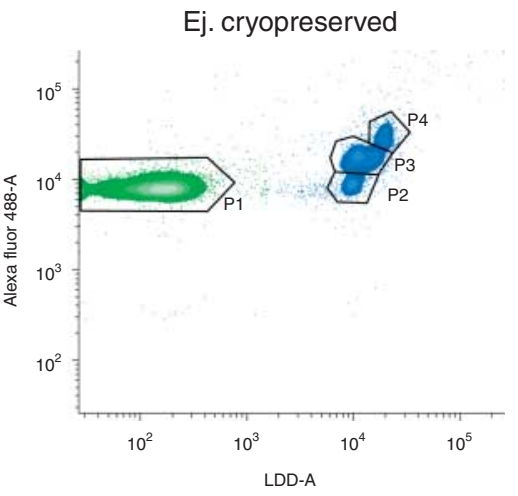
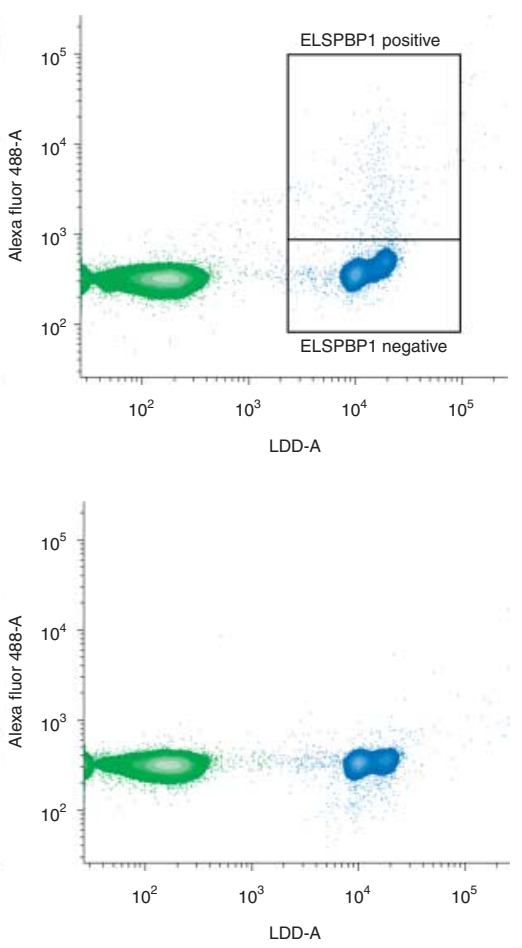

Figure 3 Immunodetection of BSP1 (A) and ELSPBP1 (B) by flow cytometry on ejaculated bovine spermatozoa before (Ej. fresh) and after cryopreservation

(Ej. cryopreserved). $X$-axis shows incorporation of the viability probe (LDD) and $Y$-axis shows level of fluorescence emitted by secondary antibody GAR Alexa 488. Spermatozoa having incorporated LDD are considered dead. Live subpopulations are shown in green and dead subpopulations are shown in blue. Fluorescence intensities are expressed as arbitrary units. Spermatozoa incubated with rabbit IgG (C) were used as negative control. Typical histograms of nine different semen samples analysed. subpopulations observed in fresh and cryopreserved semen (Fig. 5A). Spermatozoa from P1 presented labelling over the flagellum with a stronger fluorescence over the midpiece. Although P2 spermatozoa presented similar labelling over the flagellum, BSP1 was also detected on the post-acrosomal region. In spermatozoa from P3, BSP1 was detected on both the flagellar and the acrosomal region, with the posterior ring also labelled. P4 spermatozoa presented a similar fluorescence pattern as P3 spermatozoa, but with a stronger intensity. For P3 and P4 spermatozoa, labelling along the flagellum was more uniform in freshly ejaculated sperm and seemed more concentrated on the midpiece region of cryopreserved sperm. BSP1 localisation patterns varied between the three levels of fluorescence but are quite constant between fresh and cryopreserved semen. P2 spermatozoa are an exception as their fluorescence pattern was observed only in cryopreserved semen.
As all P3 sperm are alive in fresh but dead in cryopreserved semen, they represent the main sperm subpopulation sensitive to cryopreservation whereas P4 subpopulation represents spermatozoa already dead at ejaculation. In the case of P2 subpopulation, intensity comparison strongly suggests that those spermatozoa are derived from the P1 subpopulation. Interestingly, BSP1 fluorescence pattern on P2 spermatozoa does not correspond to BSP1 localisation on P1 spermatozoa. P1 spermatozoa are the only one to survive the cryopreservation process.

\section{Differences in the expression of ELSPBP1 in sperm subpopulations}

For each ejaculate analysed, ELSPBP1 was detected only in dead spermatozoa in both fresh and cryopreserved semen (Fig. 3B). These ELSPBP1-positive sperm represented $1.2 \% \pm 0.5$ of the entire population in freshly 
Table 1 Median fluorescence intensity ratios over P1 subpopulation of the subpopulations detected with BSP1 antibody as described in Figs $3 \mathrm{~A}$ and $6 \mathrm{~A}$

\begin{tabular}{lccr}
\hline & P2 & P3 & \multicolumn{1}{c}{ P4 } \\
\hline Cd epididymal+SP & - & $3.5 \pm 0.4^{*}$ & $10.7 \pm 4.2^{*}$ \\
Ej. fresh & - & $3.8 \pm 0.8^{*}$ & $9.3 \pm 2.3^{*}$ \\
Ej. cryo & $1.0 \pm 0.1$ & $2.0 \pm 0.3^{*}$ & $4.9 \pm 2.1^{*}$
\end{tabular}

Asterisk $(*)$ indicates a statistical difference of a subpopulation compared to P1. $P$ value was set at level 0.017 after the Bonferonni correction $(0.05 \div 3=0.017)$. Cd epididymal + SP, cauda epididymal spermatozoa incubated with seminal plasma; Ej. fresh, freshly ejaculated spermatozoa; Ej. cryo, ejaculated spermatozoa following cryopreservation.

ejaculated and $2.2 \% \pm 1.0$ in cryopreserved semen. However, fluorescence intensity was significantly higher in fresh semen $(16679 \pm 5980 \mathrm{MFI})$ compared with cryopreserved semen $(4357 \pm 3420 \mathrm{MFI})$, with a decrease of $74.4 \% \pm 12.6\left(P=3.7 \times 10^{-5}\right)$. Localisation of ELSPBP1 in spermatozoa was very heterogeneous. However, a fluorescent pattern found in every condition was the labelling of the acrosome and the flagellum (Fig. 5B). These results show that ELSPBP1 is found in low but comparable proportions and only on dead spermatozoa in both fresh and cryopreserved semen, suggesting that ELSPBP1 characterises a subpopulation of spermatozoa already dead at ejaculation.

\section{Binding of BSP1 on epididymal spermatozoa and measurement of ELSPBP1}

As ELSPBP1 is found on a very small proportion of ejaculated spermatozoa, we hypothesised that ELSPBP1 would be removed by BSP1 at the moment of ejaculation. This is suggested by the facts that BSP1 and ELSPBP1 would interact similarly with the plasma membrane and that ELSPBP1 is acquired by spermatozoa in the epididymis, before being exposed to BSP1, which is secreted by the seminal vesicles. Assessment of BSP1 on cauda epididymal spermatozoa pre-incubated with Sp TALPM revealed that dead spermatozoa are recognised by the antibody (Fig. 6A), with a faint signal localised over the acrosomal region (Fig. 7A). Live spermatozoa formed a homogeneous population not recognised by the anti-BSP1 antibody (Fig. 6A). When cauda epididymal spermatozoa were pre-incubated with seminal plasma, however, three distinct subpopulations were observed (Fig. 6A), which are similar to what was observed with ejaculated sperm (Fig. 3A). Fluorescence intensity ratios over P1 subpopulation are summarised in Table 1 and binding patterns are shown in Fig. 7A. These results show that co-incubation of cauda epididymal spermatozoa with seminal plasma mimics properly BSP1 binding on ejaculated spermatozoa.

Immunocytometry on cauda epididymal spermatozoa pre-incubated in Sp TALPM revealed that 5.9\% \pm 2.5 of total spermatozoa were positive for ELSPBP1, which was associated only with the dead sperm population (Fig. 6B). When the same epididymal sperm samples were incubated with seminal plasma, ELSPBP1 was still associated with dead spermatozoa in similar proportions $(5.3 \% \pm 2.1)$. These results show that ELSPBP1 is associated with spermatozoa already dead in the cauda epididymis. Interestingly, there were always more dead spermatozoa in cauda epididymal sperm pre-incubated with seminal plasma than those pre-incubated in $\mathrm{Sp}$ TALPM $(18.0 \% \pm 8.0$ vs $7.8 \% \pm 4.9 ; \quad P=0.08 ; n=3)$. Although not significant, this increase in dead spermatozoa leads to the appearance of a dead but ELSPBP1negative subpopulation (Fig. 6B), which gives a very similar subpopulation pattern to what is observed with ejaculated sperm (Fig. 3B). Still, ELSPBP1 was localised over the acrosomal region and along the flagella (Fig. 7B).

\section{Discussion}

In the context of artificial insemination with cryopreserved semen, male fertility could be influenced by the ability of spermatozoa to sustain the cryopreservation process (Van Doormaal 1993). Previously, we identified BSP1 and ELSPBP1 as more abundant in the immotile sperm population of cryopreserved bovine semen as isolated by gradient density centrifugation (D'Amours et al. 2010). In this study, we show that the presence of BSP1 over the acrosomal region characterises spermatozoa susceptible to cryopreservation-induced damages and that ELSPBP1 characterises spermatozoa that are already dead in the cauda epididymis.

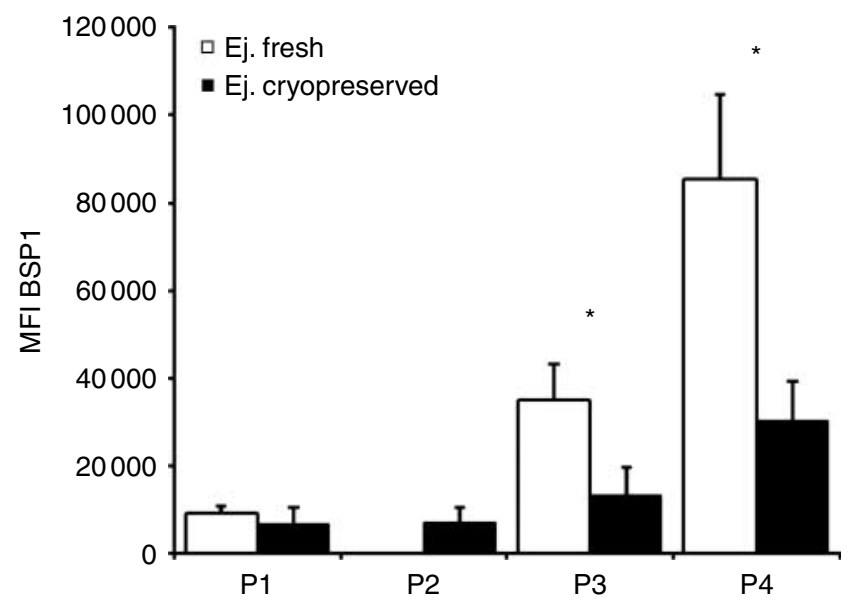

Figure 4 Comparison of median fluorescence intensity (MFI) as assessed by flow cytometry of the four subpopulations detected with BSP1 antibody and described in Fig. 3A. Freshly ejaculated semen: open square; cryopreserved semen: closed square, P2 subpopulation was compared with P1 subpopulation. Asterisk $(*)$ indicates a statistical difference of a subpopulation before and after cryopreservation. $P$ value was set at the level 0.0125 after the Bonferroni correction $(0.05 \div 4=0.0125)$. 
A

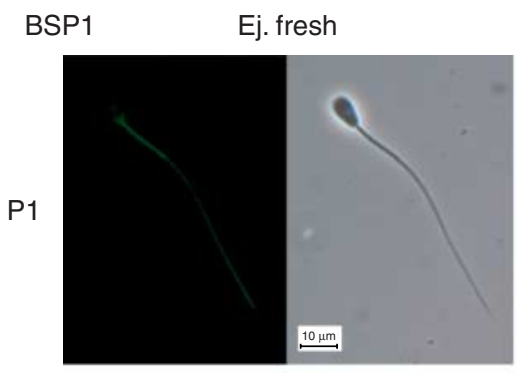

P2
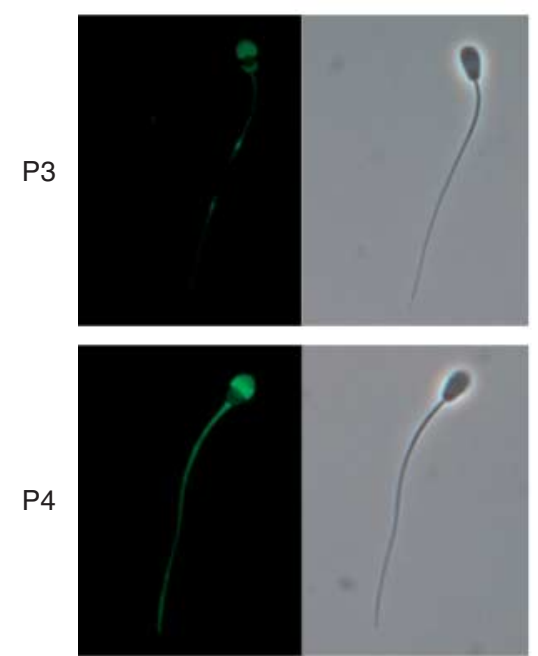

B ELSPBP1

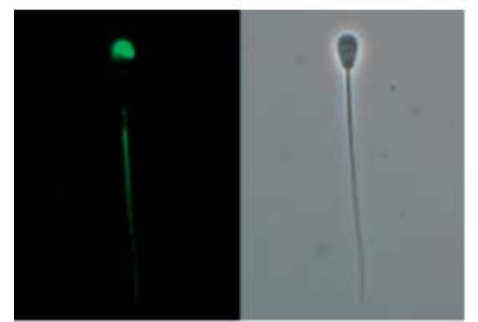

C Rabbit lgG

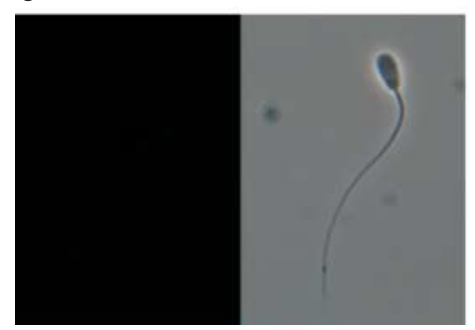

Ej. cryopreserved
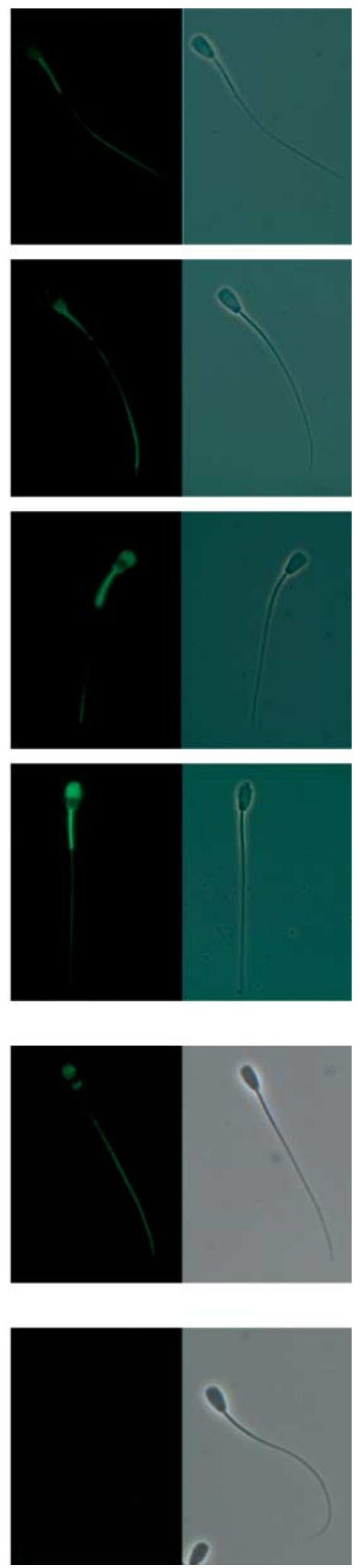

Figure 5 Fluorescence pattern of BSP1 (A) and ELSPBP1 (B) on the different subpopulations described in Fig. 3. Only spermatozoa from the ELSPBP1-positive subpopulation are shown. Spermatozoa incubated with rabbit $\operatorname{lgG}(\mathrm{C})$ were used as negative control. Original magnification: $400 \times$. Scale bar $=10 \mu \mathrm{m}$. 
Cd epididymal

A

B

ELSPBP1

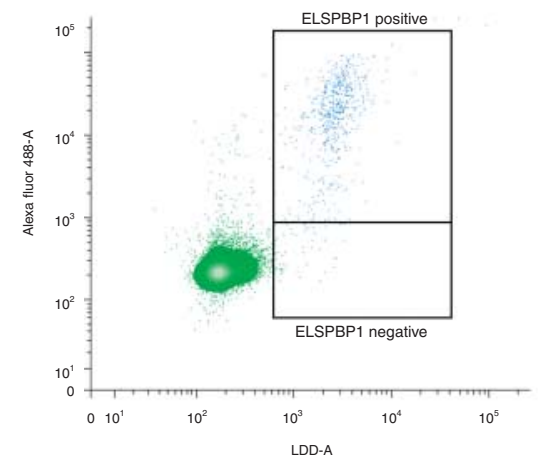

C

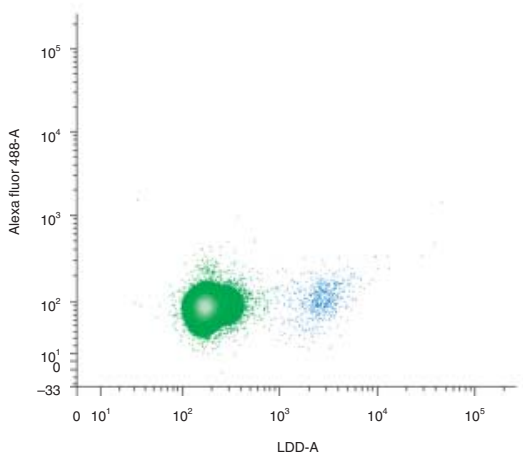

Cd epididymal+SP
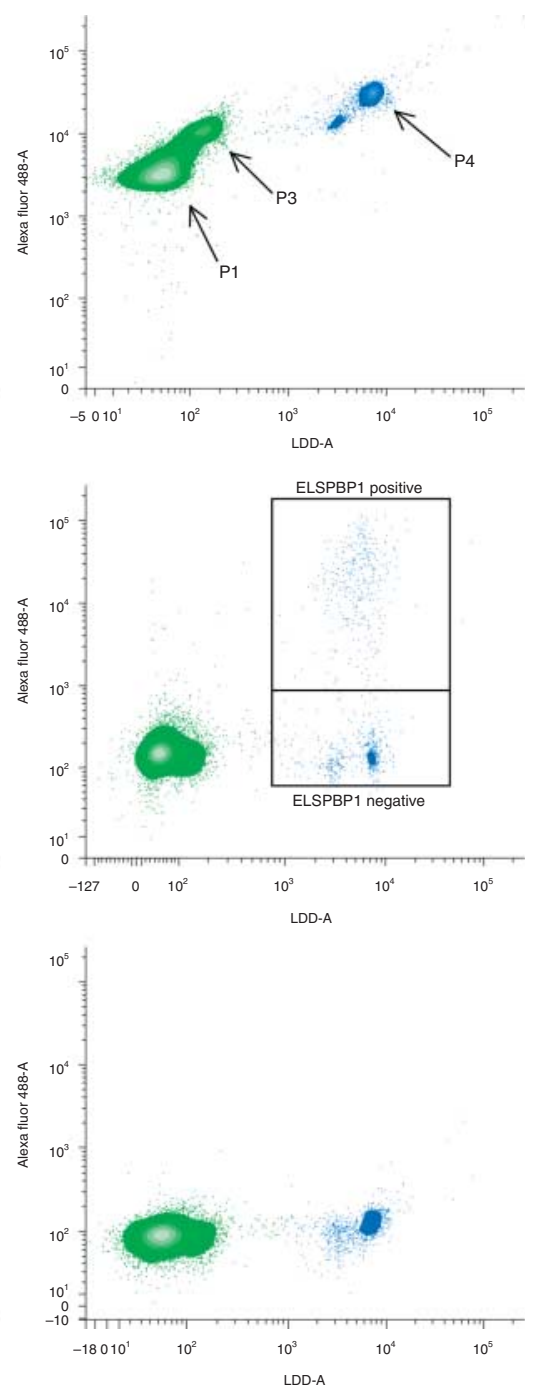

Figure 6 Immunodetection of BSP1 (A) and ELSPBP1 (B) by flow cytometry on bovine spermatozoa from cauda epididymis (Cd epididymal) incubated or not with seminal plasma (Cd epididymal + SP). $X$-axis shows incorporation of the viability probe (LDD) and $Y$-axis shows level of fluorescence emitted by secondary antibody GAR Alexa 488. Spermatozoa having incorporated LDD are considered dead. Live subpopulations are shown in green and dead subpopulations are shown in blue. Fluorescence intensities are expressed as arbitrary units. Spermatozoa incubated with rabbit $\operatorname{lgG}(\mathrm{C})$ were used as negative control. Typical histograms of three distinct experiments.
Heterogeneity in sperm BSP1 localisation has been previously reported but presents some discrepancies with our results. Immunofluorescence studies on freshly ejaculated sperm (Manjunath et al. 1994) revealed acrosomal labelling on $76-86 \%$ spermatozoa, postacrosomal labelling on $42-48 \%$ spermatozoa and uniform labelling on the midpiece region, which contrasts with our results showing that BSP1 is not detected on the head for the majority of spermatozoa (P1 subpopulation). Moreover, post-acrosomal labelling was detected only on a dead subpopulation following cryopreservation (P2 subpopulation). Although BSP1 localisation on P2 spermatozoa is different from P1 spermatozoa, both subpopulations emit the same fluorescence intensity, which suggests that P2 spermatozoa are derived from the P1 subpopulation. In that case, it means a redistribution of the protein at death. Thus, post-acrosomal localisation could be the 'dead pattern' of the P1 subpopulation. Using an immunostaining protocol similar to ours, Souza et al. (2008) observed that presence of BSP1 on the postacrosomal region of ejaculated sperm increased significantly after $5 \mathrm{~h}$ incubation in oviductal fluid for both intact and acrosome-reacted sperm. As oviductal fluid promotes capacitation (McNutt \& Killian 1991), it is likely that observed changes in BSP1 labelling pattern after $5 \mathrm{~h}$ of incubation are due to either the capacitation state of spermatozoa or their death.

Previously, quantification of BSP1 by RIA on spermatozoa revealed a high and significant decrease $(80 \%)$ in cryopreserved sperm compared with their freshly ejaculated counterparts (Nauc \& Manjunath 2000). In our study, a significant decrease in fluorescence intensity following cryopreservation is observed only on spermatozoa from P3 and P4 subpopulations (Fig. 3). Although this decrease is not as high as $80 \%$, it is limited to subpopulations of spermatozoa dead after cryopreservation and where BSP1 is detected on the acrosomal 


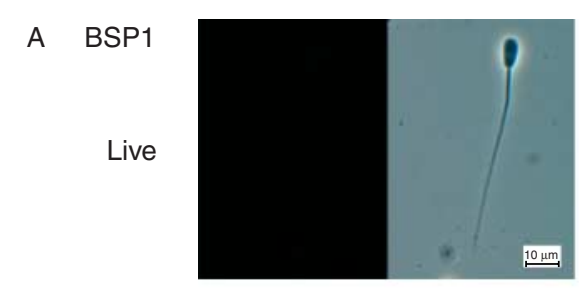

Cd epididymal

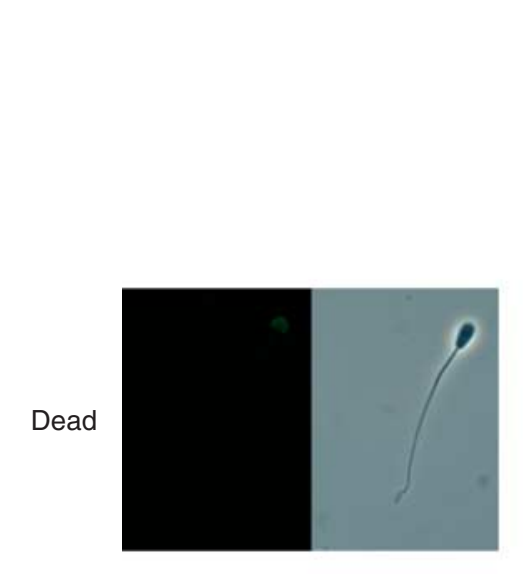

B ELSPBP1

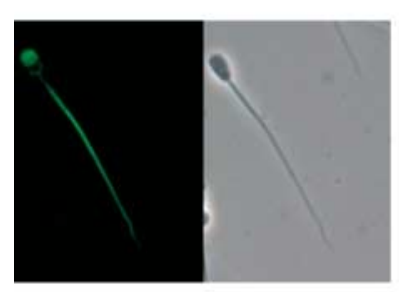

C Rabbit lgG

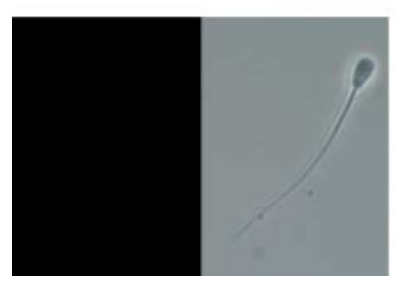

Cd epididymal+SP

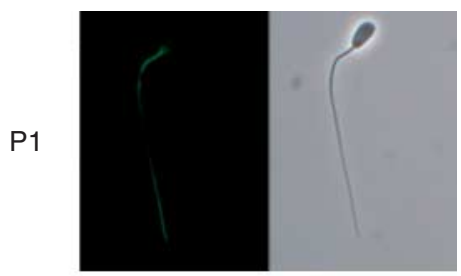

P3

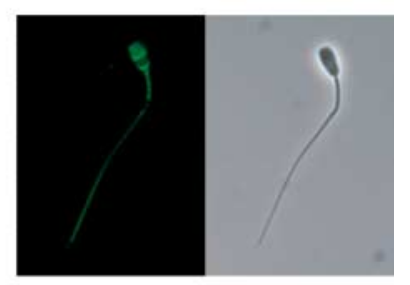

P4
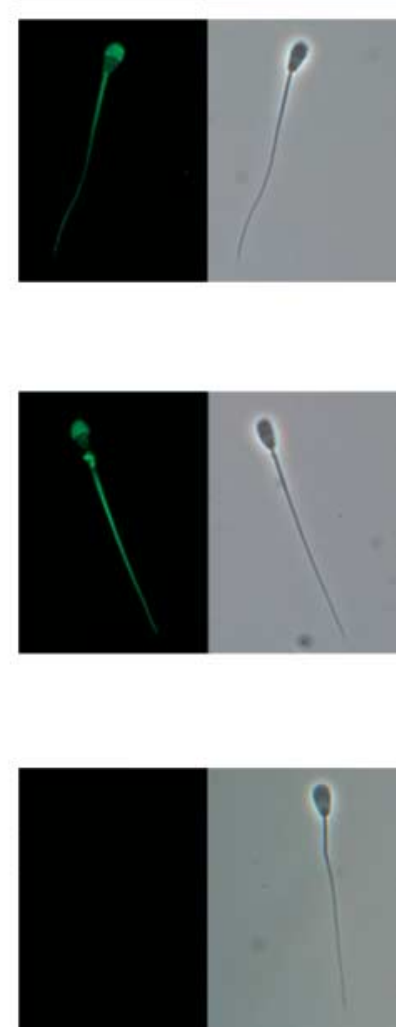

Figure 7 Fluorescence pattern of BSP1 (A) and ELSPBP1 (B) on the different subpopulations described in Fig. 6. Only spermatozoa from the ELSPBP1-positive subpopulation are shown. Spermatozoa incubated with rabbit $\operatorname{lgG}(\mathrm{C})$ were used as negative control. Original magnification: $400 \times$. Scale bar $=10 \mu \mathrm{m}$. region. Thus, it is likely that the release of BSP1 associated with the cryopreservation process mostly originates from the acrosomal region, which is in agreement with the increase in the percentage of acrosome-reacted sperm (Pons-Rejraji et al. 2009a, $2009 b$ ). Other proteins localised on the acrosomal region have been shown to be lost by spermatozoa during the cryopreservation process (Lessard et al. 2000, Desrosiers et al. 2006).

At the moment of ejaculation, BSP1 binds to the sperm surface and binding sites have been identified as phospholipids containing a phosphorylcholine moiety, namely phosphatidylcholine (PC) and sphingomyelin (SM; Desnoyers \& Manjunath 1992). Further investigations on model membranes have confirmed BSP1 specificity for PC lipids and showed its limited affinity for the other class of phospholipids and for cholesterol (Müller et al. 1998, Ramakrishnan et al. 2001, Thomas et al. 2003, Lassiseraye et al. 2008). In our study, difference between P1 and P3 spermatozoa is the presence of BSP1 over the acrosomal region of $\mathrm{P} 3$ spermatozoa. This suggests that the presence of BSP1 on the acrosomal region reflects a different lipid composition of the plasma membrane overlying the acrosome. Upon binding to spermatozoa, BSP1 induces several modifications to the plasma membrane. Incubation of epididymal spermatozoa with purified BSP1 induced cholesterol and phospholipid effluxes from the plasma 
membrane (Thérien et al. 1998, 1999). Most phospholipids released are choline phospholipid species with fatty acid patterns enriched in unsaturated, short-chain fatty acid or lysolipid (Tannert et al. 2007a). Moreover, it was observed that BSP1 induced physical perturbation of the plasma membrane by reducing fluidity of both model membranes and epididymal spermatozoa (Müller et al. 1998, Gasset et al. 2000, Greube et al. 2001). This effect of BSP1 on the physical state of the membrane is decreased in the presence of noncholine phospholipids or cholesterol in model membranes (Tannert et al. 2007 b), but increase when enriched PC lipid membranes bear short or unsaturated fatty acid chains (Greube et al. 2001). As BSP1 induced biochemical and physical modifications of the plasma membrane, it is likely that P3 spermatozoa, which present BSP1 over the acrosomal region, will experience membrane modifications different than P1 spermatozoa after ejaculation.

Dead epididymal spermatozoa are recognised by antiBSP1, and fluorescence pattern is similar to the one observed after incubation with seminal plasma. Overexposition of a western blot with different quantity of protein extracts from cauda epididymis shows a large band between 14 and $21 \mathrm{kDa}$ (data not shown), which corresponds to the apparent molecular weight of BSP1. The balance of evidences does not support an unspecific labelling but rather suggest that BSP1 is present in a minor extend on a sperm subpopulation in cauda epididymis. Incubation of epididymal spermatozoa with seminal plasma reveals the same three BSP1 fluorescence patterns as observed in ejaculated sperm. Once again, the population showing the highest fluorescence intensity is only composed of dead spermatozoa and the live sperm population is distributed among two distinct subpopulations presenting different quantity of BSP1. This result suggests that underlying characteristics favouring BSP1 binding on sperm are already present in cauda epididymal spermatozoa. Therefore, one might ask whether BSP1 is responsible for sperm susceptibility to cryopreservation, or whether it is the reflection of an underlying dysfunction of the plasma membrane, or both. Recently, a comparison between epididymal and ejaculated bovine sperm from same bulls showed that post-thaw epididymal spermatozoa presented higher percentage motility than postthaw ejaculated sperm (Alapati et al. 2009), suggesting a detrimental effect of seminal plasma on sperm sensitivity to cryopreservation. However, a previous study did not reveal any difference on post-thaw motility between cauda epididymal spermatozoa incubated or not with seminal plasma before cryopreservation (Graham 1994). So far, it is not clear whether seminal plasma mediates sperm sensitivity to cryopreservation. Nonetheless, the fact that a subpopulation of epididymal spermatozoa does not survive the cryopreservation process is unanimously accepted. We hypothesise that these spermatozoa are probably those that acquire BSP1 over the acrosomal region at ejaculation.

As inferred by X-ray diffraction, BSP1 interacts with choline head groups through its Fn2 domains (Wah et al. 2002). This leads to a partial insertion of the protein in the hydrophobic part of the membrane (Müller et al. 1998) and the consequently biochemical and physical membrane modifications discussed earlier. Sequence alignment of ELSPBP1 and BSP1 revealed that amino acid residues of the phosphorylcholine-binding pocket are strictly conserved for the two N-terminal Fn2 domains of ELSPBP1 and in silico modelling indicates a comparable secondary structure (Sahin et al. 2009). This suggests that ELSPBP1 interacts with sperm membrane in the same way as BSP1 does. For this reason, it was expected that ELSPBP1 would be found on sperm in a similar way as BSP1 and would have shown a comparable association with sperm cryosensitivity. On the contrary, ELSPBP1 was detected only on a small and comparable proportion of dead spermatozoa in both freshly ejaculated and cryopreserved semen, which rejects the hypothesis of the sperm cryosensitivity marker. Nevertheless, this explains our previous report showing that ELSPBP1 was more abundant in the immotile sperm subpopulation following cryopreservation but did not correlate with post-thaw viability (D'Amours et al. 2010). It is surprising that ELSPBP1 is found on very small number of dead spermatozoa in freshly ejaculated sperm. As ELSPBP1 and BSP1 are thought to interact similarly with sperm membranes and that ELSPBP1 is acquired by spermatozoa before BSP1, we hypothesised that ELSPBP1 could be removed by BSP1 at the time of ejaculation. Immunocytometry on spermatozoa recovered from cauda epididymis revealed that only spermatozoa from the dead population are recognised by anti-ELSPBP1 antibody. The same experiment with cauda epididymal spermatozoa incubated with seminal plasma did not reveal any significant changes in the proportion of spermatozoa recognised by anti-ELSPBP1 antibody, although it showed an increase in dead spermatozoa. These results show that ELSPBP1 is not removed by BSP1 at the moment of ejaculation and that ELSPBP1 is a marker of spermatozoa already dead in cauda epididymis. It also highlights the fact that some spermatozoa die during ejaculation. Those latter spermatozoa appear dead in epididymal spermatozoa incubated with seminal plasma but are not recognised by anti-ELSPBP1 antibody.

Since decades, sperm membranes are thought to be the main site of cryoinjuries, with their lipid composition being the determinant of sperm sensitivity to cryopreservation. In this study, we showed that the sperm subpopulation sensitive to cryopreservation is receptive to BSP1 binding over their acrosomal region. As BSP1 has affinity for specific phospholipids and induces modifications of the plasma membrane upon binding to spermatozoa, it could explain the dichotomy between 
sperm resistance and sensitivity to cryopreservation. Although BSP1 and ELSPBP1 share common primary structure and binding properties, they did not characterise the same sperm subpopulations. ELSPBP1 is associated with spermatozoa already dead before ejaculation. These results are a manifestation of semen heterogeneity and provide further evidences that biochemical characteristics can determine, in a specific context, if spermatozoa are able to reach and fertilise the oocyte. Results presented in this study are a step forward in our quest for the understanding of male subfertility/infertility.

\section{Materials and Methods}

\section{Antibody production}

\section{BSP1 purification}

Bull seminal plasma was diluted in $150 \mathrm{mM} \mathrm{NaCl}$ and centrifuged at $120000 \mathrm{~g}$ for $2 \mathrm{~h}$ at $4{ }^{\circ} \mathrm{C}$ in order to eliminate any insoluble material. Eight volumes of ice-cold ethanol was added to the supernatant and mixed for $1 \mathrm{~h}$ at $4{ }^{\circ} \mathrm{C}$. The suspension was centrifuged at $6100 \mathrm{~g}$ for $30 \mathrm{~min}$ at $4{ }^{\circ} \mathrm{C}$ in a JS 5.3 rotor. The pellet was washed once with ice-cold ethanol. The pellet was solubilised in water (protein concentration $=16 \mathrm{mg} / \mathrm{ml}$ ) and then lyophilised. Proteins (50-55 mg) were dissolved in $4 \mathrm{ml}$ of $10 \mathrm{mM}$ dibasic sodium phosphate, $\mathrm{pH} 7.0$, and centrifuged at $10000 \mathrm{~g}$ for $10 \mathrm{~min}$ at $4{ }^{\circ} \mathrm{C}$. The supernatant was chromatographed on a $12 \mathrm{ml} \mathrm{CM}$-Sepharose column equilibrated in $10 \mathrm{mM}$ dibasic sodium phosphate, $\mathrm{pH}$ 7.0, to remove basic proteins, especially HE1, also known as NPC2. The unretained proteins were diluted with one volume of $50 \mathrm{mM}$ dibasic sodium phosphate, $\mathrm{pH} 7.4$ (buffer A), and applied on heparin-Sepharose affinity column equilibrated in buffer A. The column was washed with at least $50 \mathrm{ml}$ buffer A till the absorbance $(280 \mathrm{~nm})$ reached 0.025 . The proteins were eluted in $40 \mathrm{mM}$ dibasic sodium phosphate, $\mathrm{pH} 7.4$, containing $1 \mathrm{M} \mathrm{NaCl}$ and then chromatographed on a $250 \mathrm{ml}$ Sephadex G-100 column at a flow rate of $30 \mathrm{ml} / \mathrm{h}$ in $20 \mathrm{mM}$ dibasic sodium phosphate, $\mathrm{pH} 7.4$, containing $150 \mathrm{mM} \mathrm{NaCl}$. Purification was assessed by SDS-PAGE. Purified BSP1 was store at $-20^{\circ} \mathrm{C}$ until rabbit immunisation.

\section{Recombinant ELSPBP1 fragment production}

The amino acid 101-160 sequence of bovine ELSPBP1 was chosen as antigen based on protein hydrophobicity and protein secondary structure prediction algorithms (Kyte \& Doolittle 1982, Deleage \& Roux 1987) using ExPASy Proteomics tools (http://ca.expasy.org/tools/). To generate this fragment, full-length bovine ELSPBP1 was first introduced into a cloning vector. Briefly, total RNA extracted from bovine cauda epididymal tissue was reverse transcribed using Superscript II (Invitrogen). 5'-ATG AAT GGA TGG CCC AGT TAC- $3^{\prime}$ and $5^{\prime}$-TCA GCA GTA CAC CCA AGT GTG-3' forward and reverse primers, respectively, were designed to amplify the full length of bovine ELSPBP1 with Taq DNA Polymerase (NEB, Cat. No. M0267L, Pickering, ON, Canada). The PCR conditions were as follows: initial denaturation at $95^{\circ} \mathrm{C}$ for 5 min followed by 40 cycles of denaturation at $95^{\circ} \mathrm{C}$ for $1 \mathrm{~min}$, annealing at $60^{\circ} \mathrm{C}$ for $1 \mathrm{~min}$ and extension at $72^{\circ} \mathrm{C}$ for $1 \mathrm{~min}$. The PCR product was purified using the QIAquick PCR purification kit (Qiagen), cloned in pGEM-T-Easy (Promega Corp.), transformed into DH $5 \alpha$ cells and sequenced by the core facilities of our institution. Another set of primers containing Ndel and Xhol restrictions sites in the forward and reverse primers, respectively, were used to amplify the ELSPBP1 portion corresponding to amino acid 101-160 from the plasmid (forward: 5'-CAT ATG TCA GTC ACT TCC AGC TTT GAT G-3'; reverse: 5'-CTC GAG ATC CAT GTT CTC CGT GGT TGG A-3 $3^{\prime}$. The PCR conditions were as follows: initial denaturation at $95^{\circ} \mathrm{C}$ for 5 min followed by 30 cycles of denaturation at $95^{\circ} \mathrm{C}$ for $30 \mathrm{~s}$, annealing at $55^{\circ} \mathrm{C}$ for $30 \mathrm{~s}$ and extension at $72{ }^{\circ} \mathrm{C}$ for $30 \mathrm{~s}$. PCR product was purified using the QIAquick PCR purification kit (Qiagen), inserted into pET 21b vector (Novagen, Gibbstown, NJ, USA), transformed into DH5 $\alpha$ cells, amplified and sequenced. BL21 (DE3) bacteria (Novagen) were transformed with the pET 21b-ELSPBP1 plasmid, and His-tagged recombinant protein fragment overexpression was induced with $1 \mathrm{mM}$ isopropylb-D-thiogalactopyranoside. The cells were sonicated in $20 \mathrm{mM}$ Tris and $500 \mathrm{mM} \mathrm{NaCl}$ (pH 8.0; buffer B), and the soluble rec-ELSPBP1 fragment was purified on ProBound resin according to the supplier's instructions (Invitrogen). Briefly, the clear supernatant was applied on a $1 \mathrm{ml}$ Probound resin column. The column was washed successively with three volumes of buffer B containing $60 \mathrm{mM}$ imidazole. The rec-ELSPBP1 fragment was eluted with buffer B containing $500 \mathrm{mM}$ imidazole, dialysed against $150 \mathrm{mM} \mathrm{NaCl}$ and store at $-80{ }^{\circ} \mathrm{C}$ until rabbit immunisation. Purification was assessed by SDS-PAGE.

\section{Rabbit immunisation}

New Zealand female rabbits were immunised with $300 \mu \mathrm{g}$ of either purified BSP1 or rec-ELSPBP1 fragment in $150 \mathrm{mM} \mathrm{NaCl}$ mixed with an equal volume of Freund complete adjuvant. Boost injections were given every 4-5 weeks with $150 \mu \mathrm{g}$ of the antigen emulsified in incomplete adjuvant. Specific anti-BSP1 and anti-ELSPBP1 antibodies were purified by affinity chromatography against their respective antigen immobilised on $\mathrm{CNBr}$ activated Sepharose (Pharmacia) using standard procedure. Specificity of antibodies was assessed by probing western blots of ejaculated sperm protein extracts.

\section{Animals and semen processing}

Freshly ejaculated semen and corresponding frozen semen from nine mature Holstein bulls were generously provided by L'Alliance Boviteq, Inc. (Saint-Hyacinthe, QC, Canada). Bulls were housed at Centre d'Insémination Artificielle du Québec (CIAQ; Sainte-Madeleine, QC, Canada) and semen was collected and processed for quality control by CIAQ technicians. Semen was diluted in Tris-based egg yolk extender and frozen in liquid nitrogen according to standard A.I. procedures. Each ejaculate met the minimal quality controls following ejaculation and cryopreservation. Freshly ejaculated semen was diluted in Sp TALPH (described by Parrish et al. (1988) and modified by Galantino-Homer et al. (1997)): $114 \mathrm{mM} \mathrm{NaCl}$, $3.1 \mathrm{mM} \mathrm{KCl}, 2 \mathrm{mM} \mathrm{NaHCO}, 0.3 \mathrm{mM} \mathrm{NaH}_{2} \mathrm{PO}_{4}, 2 \mathrm{mM} \mathrm{CaCl}_{2}$, $0.5 \mathrm{mM} \mathrm{MgCl} 2,10 \mathrm{mM}$ sodium lactate, $0.2 \mathrm{mM}$ pyruvate, 
$10 \mathrm{mM}$ HEPES and $1 \mathrm{mg} / \mathrm{ml}$ polyvinyl alcohol, $\mathrm{pH}$ 7.4) then processed for immunocytometry as described below within $30 \mathrm{~min}$ following ejaculation. Cryopreserved semen was thawed for $1 \mathrm{~min}$ in a $38.5^{\circ} \mathrm{C}$ water bath and then processed for immunocytometry as described below. Cryopreserved semen was analysed at least 1 week after collection.

\section{Immunocytometry analysis and fluorescent-activated cell sorting}

$30 \times 10^{6}$ freshly ejaculated or cryopreserved spermatozoa were washed once in Sp TALPH and then incubated for $10 \mathrm{~min}$ at $34.5^{\circ} \mathrm{C}$ in $2 \mathrm{ml} \mathrm{Sp}$ TALPH containing $1.8 \mu$ l working solution of LIVE/DEAD Fixable Near-IR Dead Cell Stain (Invitrogen, Cat. No. L10119; hereafter called LDD). Spermatozoa were fixed with $3.7 \%$ formaldehyde for $15 \mathrm{~min}$ and then Triton X-100 $(0.2 \%$ final concentration) was added to sperm suspensions for permeabilisation and incubated for $15 \mathrm{~min}$. Spermatozoa were washed by centrifugation with PBS $(137 \mathrm{mM} \mathrm{NaCl}, 3 \mathrm{mM} \mathrm{KCl}$, $8 \mathrm{mM} \mathrm{Na}_{2} \mathrm{HPO}_{4}$ and $1.5 \mathrm{mM} \mathrm{KH}_{2} \mathrm{PO}_{4}, \mathrm{pH} 7.3$ ), resuspended in PBS supplemented with $1 \%(\mathrm{w} / \mathrm{v})$ BSA and blocked for $30 \mathrm{~min}$. Sperm concentration was adjusted to $15 \times 10^{6} / \mathrm{ml}$, anti-BSP1, anti-ELSPBP1 or purified rabbit IgG was added to sperm suspensions at a final concentration of $5 \mu \mathrm{g} / \mathrm{ml}$ and incubated for $1 \mathrm{~h}$ at $38.5^{\circ} \mathrm{C}$. Spermatozoa were washed by centrifugation in PBS and resuspended in 1\% BSA-containing PBS added with $2 \mu \mathrm{g} / \mathrm{ml}$ Alexa Fluor 488-conjugated goat antirabbit antibody and $5 \mu \mathrm{g} / \mathrm{ml}$ Hoechst 33342 (Invitrogen, Cat. No. A-11034 and H-3570). Spermatozoa were incubated with the secondary antibody for $30 \mathrm{~min}$ at $38.5^{\circ} \mathrm{C}$, resuspended in PBS and fluorescence measured with LSRII flow cytometer (Becton Dickinson, San Jose, CA, USA). Ten thousand 'Hoechst positive' events were recorded for each reading. Probes were read using the following laser and filter combinations: Hoechst 33342: $355 \mathrm{~nm}$ u.v. laser and a 450/50 band pass filter; Alexa Fluor 488-conjugated goat-anti rabbit IgG: $488 \mathrm{~nm}$ laser and a 530/30 band pass filter; LDD: $633 \mathrm{~nm}$ laser and a 780/60 band pass filter. Figure 2 shows the detection of the three colours of the immunocytometry assay using detection of BSP1 on freshly ejaculated sperm. Fluorescence intensity was calculated on an arbitrary scale and median (MFI) was used as measures of location for detected populations. Data were analysed with BD FacsDiva version 5.0.3 (Becton Dickinson).

Alternatively, sperm populations defined in Figs 3 and 6 were sorted by a FACS Aria II flow cytometer (Becton Dickinson). Probes were read using the following laser and filter combinations: Hoechst 33342: $375 \mathrm{~nm}$ near-u.v. laser and a 450/50 band pass filter; Alexa Fluor 488 goat-anti rabbit conjugated: $488 \mathrm{~nm}$ laser and a 525/25 band pass filter; LDD: $633 \mathrm{~nm}$ laser and a 780/60 band pass filter. After cell sorting, $10 \mu \mathrm{l}$ aliquots were deposited on microscopic slides and immune complexes were visualised with a Zeiss Axioskop 2 plus microscope equipped with a XF71 filter (Omega Optical, Brattleboro, VT, USA) for the visualisation of Alexa Fluor 488.

\section{Epididymal spermatozoa incubated in seminal plasma}

Bovine testes with attached epididymis were obtained from a local slaughterhouse and brought to the laboratory within $2 \mathrm{~h}$ on ice. Tissues were dissected upon arrival and only epididymides presenting normal morphology were used to recover spermatozoa. Cauda epididymal spermatozoa were collected by applying retrograde air pressure into the vas deferens cannulated with a syringe. One hundred microlitres of cauda epididymal fluid containing spermatozoa were diluted in either $1 \mathrm{ml}$ bovine seminal plasma or $1 \mathrm{ml}$ Sp TALPM (Sp TALPH with HEPES replaced by MES and $\mathrm{pH}$ adjusted to 6.5) pre-heated to $37^{\circ} \mathrm{C}$. Sp TALPM was adjusted to $\mathrm{pH} 6.5$ to mimic cauda epididymal fluid $\mathrm{pH}$. Spermatozoa were incubated for $30 \mathrm{~min}$ at room temperature. After incubation, spermatozoa were assessed for the presence of BSP1 or ELSPBP1 by flow cytometry as described earlier with the exception that control spermatozoa were washed and incubated with viability probe (LDD) in Sp TALPM. Experiment was done three times on three different weeks using seminal plasma from a single ejaculate.

\section{Statistical analysis}

Results are presented as mean \pm s.D. Median fluorescence intensities or proportions were compared by paired $t$-test and significance level set at $P<0.05$ (bilateral) and then corrected by the Bonferroni correction.

\section{Declaration of interest}

The authors declare that there is no conflict of interest that could be perceived as prejudicing the impartiality of the research reported.

\section{Funding}

This work was supported by grants from the Natural Sciences and Engineering Research Council of Canada (NSERC) and L'Alliance Boviteq, Inc. (LAB) to R Sullivan and P Leclerc. O D'Amours is supported by a PhD scholarship from NSERC and 'Fond Québécois de Recherche sur la Nature et les Technologies'.

\section{Acknowledgements}

CIAQ and LAB employees are acknowledged for their technical assistance with semen evaluation and cryopreservation.

\section{References}

Alapati R, Stout M, Saenz J, Gentry GT Jr, Godke RA \& Devireddy RV 2009 Comparison of the permeability properties and post-thaw motility of ejaculated and epididymal bovine spermatozoa. Cryobiology $\mathbf{5 9}$ 164-170. (doi:10.1016/j.cryobiol.2009.06.009)

Barbas JP \& Mascarenhas RD 2009 Cryopreservation of domestic animal sperm cells. Cell and Tissue Banking 10 49-62. (doi:10.1007/s10561008-9081-4)

Barbonetti A, Vassallo MR, Cinque B, Antonangelo C, Sciarretta F, Santucci R, D'Angeli A, Francavilla S \& Francavilla F 2008 Dynamics of the global tyrosine phosphorylation during capacitation and acquisition of the ability to fuse with oocytes in human spermatozoa. Biology of Reproduction 79 649-656. (doi:10.1095/biolreprod.108. 068254) 
D'Amours O, Frenette G, Fortier M, Leclerc P \& Sullivan R 2010 Proteomic comparison of detergent-extracted sperm proteins from bulls with different fertility indexes. Reproduction 139 545-556. (doi:10.1530/ REP-09-0375)

Darin-Bennett A \& White IG 1977 Influence of the cholesterol content of mammalian spermatozoa on susceptibility to cold-shock. Cryobiology 14 466-470. (doi:10.1016/0011-2240(77)90008-6)

Deleage G \& Roux B 1987 An algorithm for protein secondary structure prediction based on class prediction. Protein Engineering 1 289-294. (doi:10.1093/protein/1.4.289)

De Leeuw FE, Chen HC, Colenbrander B \& Verkleij AJ 1990 Cold-induced ultrastructural changes in bull and boar sperm plasma membranes. Cryobiology 27 171-183. (doi:10.1016/0011-2240(90)90009-S)

Den Daas JH, De Jong G, Lansbergen LM \& Van Wagtendonk-De Leeuw AM 1998 The relationship between the number of spermatozoa inseminated and the reproductive efficiency of individual dairy bulls. Journal of Dairy Science $\mathbf{8 1}$ 1714-1723. (doi:10.3168/jds.S00220302(98)75739-X)

Desnoyers L \& Manjunath P 1992 Major proteins of bovine seminal plasma exhibit novel interactions with phospholipid. Journal of Biological Chemistry 267 10149-10155.

Desrosiers P, Legare C, Leclerc P \& Sullivan R 2006 Membranous and structural damage that occur during cryopreservation of human sperm may be time-related events. Fertility and Sterility 85 1744-1752. (doi:10.1016/j.fertnstert.2005.11.046)

Esch FS, Ling NC, Bohlen P, Ying SY \& Guillemin R 1983 Primary structure of PDC-109, a major protein constituent of bovine seminal plasma. Biochemical and Biophysical Research Communications 113 861-867. (doi:10.1016/0006-291X(83)91078-1)

Galantino-Homer HL, Visconti PE \& Kopf GS 1997 Regulation of protein tyrosine phosphorylation during bovine sperm capacitation by a cyclic adenosine $3^{\prime} 5^{\prime}$-monophosphate-dependent pathway. Biology of Reproduction 56 707-719. (doi:10.1095/biolreprod56.3.707)

Gasset M, Magdaleno L \& Calvete J 2000 Biophysical study of the perturbation of model membrane structure caused by seminal plasma protein PDC-109. Archives of Biochemistry and Biophysics 374 241-247. (doi:10.1006/abbi.1999.1593)

Graham JK 1994 Effect of seminal plasma on the motility of epididymal and ejaculated spermatozoa of the ram and bull during the cryopreservation process. Theriogenology 41 1151-1162. (doi:10.1016/S0093691X(05)80037-8)

Greube A, Muller K, Topfer-Petersen E, Herrmann A \& Muller P 2001 Influence of the bovine seminal plasma protein PDC-109 on the physical state of membranes. Biochemistry 40 8326-8334. (doi:10.1021/ bi010552+)

Kyte J \& Doolittle RF 1982 A simple method for displaying the hydropathic character of a protein. Journal of Molecular Biology 157 105-132. (doi:10.1016/0022-2836(82)90515-0)

Lassiseraye D, Courtemanche L, Bergeron A, Manjunath P \& Lafleur M 2008 Binding of bovine seminal plasma protein BSP-A1/-A2 to model membranes: lipid specificity and effect of the temperature. Biochimica et Biophysica Acta 1778 502-513. (doi:10.1016/j.bbamem.2007.10.025)

Lessard C, Parent S, Leclerc P, Bailey JL \& Sullivan R 2000 Cryopreservation alters the levels of the bull sperm surface protein P25b. Journal of Andrology 21 700-707.

Manjunath P \& Thérien I 2002 Role of seminal plasma phospholipidbinding proteins in sperm membrane lipid modification that occurs during capacitation. Journal of Reproductive Immunology 53 109-119. (doi:10.1016/S0165-0378(01)00098-5)

Manjunath P, Sairam MR \& Uma J 1987 Purification of four gelatin-binding proteins from bovine seminal plasma by affinity chromatography. Bioscience Reports 7 231-238. (doi:10.1007/BF01124794)

Manjunath P, Chandonnet L, Leblond E \& Desnoyers L 1994 Major proteins of bovine seminal vesicles bind to spermatozoa. Biology of Reproduction 50 27-37. (doi:10.1095/biolreprod50.1.27)

Martinez-Pastor F, Mata-Campuzano M, Alvarez-Rodriguez M, Alvarez M, Anel L \& de Paz P 2010 Probes and techniques for sperm evaluation by flow cytometry. Reproduction in Domestic Animals 45 (Suppl 2) 67-78. (doi:10.1111/j.1439-0531.2010.01622.x)

McNutt TL \& Killian GJ 1991 Influence of bovine follicular and oviduct fluids on sperm capacitation in vitro. Journal of Andrology 12 244-252.
Medeiros CM, Forell F, Oliveira AT \& Rodrigues JL 2002 Current status of sperm cryopreservation: why isn't it better? Theriogenology 57 327-344. (doi:10.1016/S0093-691X(01)00674-4)

Müller P, Erlemann KR, Muller K, Calvete J, Topfer-Petersen E, Marienfeld K \& Herrmann A 1998 Biophysical characterization of the interaction of bovine seminal plasma protein PDC-109 with phospholipid vesicles. European Biophysics Journal 27 33-41. (doi:10.1007/ s002490050108)

Nauc V \& Manjunath P 2000 Radioimmunoassays for bull seminal plasma proteins (BSP-A1/-A2, BSP-A3, and BSP-30-Kilodaltons), and their quantification in seminal plasma and sperm. Biology of Reproduction 63 1058-1066. (doi:10.1095/biolreprod63.4.1058)

Parrish JJ, Susko-Parrish J, Winer MA \& First NL 1988 Capacitation of bovine sperm by heparin. Biology of Reproduction 38 1171-1180. (doi:10.1095/biolreprod38.5.1171)

Parrish JJ, Krogenaes A \& Susko-Parrish JL 1995 Effect of bovine sperm separation by either swim-up or Percoll method on success of in vitro fertilization and early embryonic development. Theriogenology $4 \mathbf{4}$ 859-869. (doi:10.1016/0093-691X(95)00271-9)

Piehler E, Petrunkina AM, Ekhlasi-Hundrieser M \& Topfer-Petersen E 2006 Dynamic quantification of the tyrosine phosphorylation of the sperm surface proteins during capacitation. Cytometry. Part A 69 1062-1070. (doi:10.1002/cyto.a.20338)

Pons-Rejraji H, Bailey JL \& Leclerc P 2009a Cryopreservation affects bovine sperm intracellular parameters associated with capacitation and acrosome exocytosis. Reproduction, Fertility, and Development 21 525-537. (doi:10.1071/RD07170)

Pons-Rejraji H, Bailey JL \& Leclerc P 2009b Modulation of bovine sperm signalling pathways: correlation between intracellular parameters and sperm capacitation and acrosome exocytosis. Reproduction, Fertility, and Development 21 511-524. (doi:10.1071/RD07169)

Poulos A, Darin-Bennett A \& White IG 1973 The phospholipid-bound fatty acids and aldehydes of mammalian spermatozoa. Comparative Biochemistry and Physiology, Part B 46 541-549. (doi:10.1016/03050491(73)90094-1)

Ramakrishnan M, Anbazhagan V, Pratap TV, Marsh D \& Swamy MJ 2001 Membrane insertion and lipid-protein interactions of bovine seminal plasma protein PDC-109 investigated by spin-label electron spin resonance spectroscopy. Biophysical Journal 81 2215-2225. (doi:10.1016/S0006-3495(01)75869-9)

Saalmann A, Munz S, Ellerbrock K, Ivell R \& Kirchhoff C 2001 Novel spermbinding proteins of epididymal origin contain four fibronectin type II-modules. Molecular Reproduction and Development 58 88-100. (doi:10.1002/1098-2795(200101)58:1 <88::AID-MRD12>3.0.CO;2-D)

Sahin E, Petrunkina AM, Ekhlasi-Hundrieser M, Hettel C, Waberski D, Harrison RA \& Topfer-Petersen E 2009 Fibronectin type II-module proteins in the bovine genital tract and their putative role in cell volume control during sperm maturation. Reproduction, Fertility, and Development 21 479-488. (doi:10.1071/RD08209)

Shannon P \& Vishwanath R 1995 The effect of optimal and suboptimal concentrations of sperm on the fertility of fresh and frozen bovine semen and a theoretical model to explain the fertility differences. Animal Reproduction Science 39 1-10. (doi:10.1016/0378-4320(95)01376-B)

Sherman JK \& Liu KC 1982 Ultrastructure before freezing, while frozen, and after thawing in assessing cryoinjury of mouse epididymal spermatozoa. Cryobiology 19 503-510. (doi:10.1016/0011-2240(82)90179-1)

Souza CE, Moura AA, Monaco E \& Killian GJ 2008 Binding patterns of bovine seminal plasma proteins A1/A2, $30 \mathrm{kDa}$ and osteopontin on ejaculated sperm before and after incubation with isthmic and ampullary oviductal fluid. Animal Reproduction Science 105 72-89. (doi:10.1016/ j.anireprosci.2007.11.027)

Sutovsky P, Neuber E \& Schatten G 2002 Ubiquitin-dependent sperm quality control mechanism recognizes spermatozoa with DNA defects as revealed by dual ubiquitin-TUNEL assay. Molecular Reproduction and Development 61 406-413. (doi:10.1002/mrd.10101)

Sutovsky P, Turner RM, Hameed S \& Sutovsky M 2003 Differential ubiquitination of stallion sperm proteins: possible implications for infertility and reproductive seasonality. Biology of Reproduction 68 688-698. (doi:10.1095/biolreprod.102.005306)

Tannert A, Kurz A, Erlemann KR, Muller K, Herrmann A, Schiller J, Topfer-Petersen E, Manjunath P \& Muller P 2007a The bovine seminal 
plasma protein PDC-109 extracts phosphorylcholine-containing lipids from the outer membrane leaflet. European Biophysics Journal 36 461-475. (doi:10.1007/s00249-006-0105-3)

Tannert A, Topfer-Petersen E, Herrmann A, Muller K \& Muller P $2007 b$ The lipid composition modulates the influence of the bovine seminal plasma protein PDC-109 on membrane stability. Biochemistry 46 11621-11629. (doi:10.1021/bi7011299)

Thérien I, Moreau R \& Manjunath P 1998 Major proteins of bovine seminal plasma and high-density lipoprotein induce cholesterol efflux from epididymal sperm. Biology of Reproduction 59 768-776. (doi:10.1095/ biolreprod59.4.768)

Thérien I, Moreau R \& Manjunath P 1999 Bovine seminal plasma phospholipid-binding proteins stimulate phospholipid efflux from epididymal sperm. Biology of Reproduction 61 590-598. (doi:10.1095/ biolreprod61.3.590)

Thomas CJ, Anbazhagan V, Ramakrishnan M, Sultan N, Surolia I \& Swamy MJ 2003 Mechanism of membrane binding by the bovine seminal plasma protein, PDC-109: a surface plasmon resonance study. Biophysical Journal 84 3037-3044. (doi:10.1016/S0006-3495 (03)70029-0)

Van Doormaal BJ 1993 Linear evaluations of non-return rates for dairy and beef bulls in Canadian Al. Canadian Journal of Animal Science 73 795-804. (doi:10.4141/cjas93-082)

Wah DA, Fernandez-Tornero C, Sanz L, Romero A \& Calvete II 2002 Sperm coating mechanism from the 1.8 A crystal structure of PDC-109phosphorylcholine complex. Structure 10 505-514. (doi:10.1016/ S0969-2126(02)00751-7)

Received 17 October 2011

First decision 21 November 2011

Revised manuscript received 22 February 2012

Accepted 27 March 2012 